Cadernos de Pesquisa do CDHIS

\title{
A “PACIFICAÇÃO” DE ACORDO COM O DIRETÓRIO POMBALINO E SUA REALIDADE NOS ALDEAMENTOS DE MARIA I E SÃO JOSÉ DE MOSSÂMEDES
}

THE “PACIFICATION" ACCORDING TO THE POMBALINE DIRECTORY AND ITS REALITY IN THE VILLAGES OF MARIA I AND SÃO JOSÉ DE MOSSÂMEDES

Gabriel Zissi Peres Asnis ${ }^{1}$

\footnotetext{
${ }^{1}$ Graduado em História e Mestre em Ciências Sociais pelo Programa de Pós-Graduação em Ciências Sociais da Universidade Federal de Uberlândia. Membro da equipe de Arqueologia da Fundação Araporã - Araraquara, SP. Pesquisador do Grupo de Estudos em Arqueologia, Etnologia e História Indígena (GEPAEHI) da Universidade Federal de Uberlândia. E-mail: gabrielasnis@gmail.com
} 


\section{RESUMO}

$\mathrm{O}$ artigo busca desconstruir a imagem de que os aldeamentos de Maria I e São José de Mossâmedes construídos na antiga capitania de Goiás, no século XVIII, sob as exigências do Diretório pombalino, tiveram como pressuposto a "pacificação" da relação entre agentes coloniais e populações indígenas que habitavam o Brasil central - mais especificadamente os "Cayapó" descritos na documentação histórica -. A "pacificação" no período colonial, de acordo com João Pacheco de Oliveira Filho (2016), tinha o objetivo de fazer surgir um "novo índio", cristão e súdito fiel do rei de Portugal, além de servir como mão-de-obra para os interesses econômicos da coroa. Ou seja, a premissa da "pacificação" nada mais era do que a de impor um modelo cultural para os indígenas, que receberiam em troca o "cessar fogo" dos ataques que vinham sofrendo desde o primeiro contato, em 1723. Em contrapartida, buscar-se-á compreender como que o conceito da "pacificação" foi apropriado por esses grupos denominados "Cayapó" para a concretização de seus próprios interesses. Veremos que se antes da construção dos aldeamentos essas populações seguiam uma lógica da guerra para aquisição de bens materiais e culturais, ou seja, uma prática da estrutura, agora passa a haver uma estrutura da prática, tal como teorizado por Marshall Sahlins (1990; 2008), em que novas formas de se relacionarem com a alteridade entram em jogo, causando uma redefinição da guerra para ambos os lados, sendo esse o ponto chave do trabalho.

Palavras-chave: Aldeamentos em Goiás; "Cayapó"; Diretório pombalino; "Pacificação".

\section{ABSTRACT}

The paper seeks to deconstruct the image that the settlements of Maria I and São José de Mossâmedes built in the old captaincy of Goiás in the eighteenth century, under the requirements of the Pombaline Directory, had a presupposition the "pacification" of the relation between colonial agents and populations indigenous people who inhabited Central Brazil - more specifically the "Cayapó" described in historical documentation. The "pacification" in the colonial period, according to João Pacheco de Oliveira Filho (2016), had the objective of raising a "new Native", Christian and faithful subject of the king of Portugal, besides serving as a labor force for the economic interests of the crown. That is to say, the premise of "pacification" was nothing more than that of imposing a cultural model for the natives, who would receive in exchange the "ceasefire" of the attacks they had been suffering since their first contact in 1723. On the other hand, it will be understood how the concept of "pacification" was appropriated by these groups called "Cayapó" for the realization of their own interests. We will see that if prior to the construction of settlements these populations followed a logic of war for the acquisition of material and cultural goods, that is, a practice of structure, there is now a structure of practice, as theorized by Marshall Sahlins (1990; 2008), in which new ways of relating to otherness come into play, causing a redefinition of the war for both sides, being the key point of the work.

Keywords: Villages in Goiás; "Cayapó"; Pombaline Directory; "Pacification". 


\section{Contextos históricos e o surgimento do termo "Cayapó"}

Os primeiros contatos estabelecidos entre os povos indígenas que habitavam a região dos atuais norte de São Paulo, Triângulo Mineiro, sul de Goiás e leste do Mato Grosso do Sul e as frentes coloniais se deram seguramente a partir de 1722, quando o bandeirante Bartolomeu Bueno da Silva, o conhecido Anhanguera, ${ }^{2}$ saiu em busca das minas de ouro na região da Serra Dourada, no atual estado de Goiás, explorando o "caminho dos Goiases", que ligava a capitania de São Paulo ao arraial de Santa Ana, ${ }^{3}$ possibilitando a exploração das minas e a ocupação do interior da América portuguesa pelos não-índios.

A expedição saiu de São Paulo no dia 3 de julho de 1722. O principal objetivo da campanha era o de descobrir ouro e diamante, muito em virtude dos rumores de locais míticos abarrotados de pedras preciosas. Outros importantes objetivos foram abrir uma estrada por terra até as minas de Cuiabá, visto que os caminhos eram em grande parte fluviais (as chamadas monções) e de difícil empreitada, e o de expandir o território da capitania de São Paulo.

É nessa conjuntura histórica que vai surgir pela primeira vez o termo "Cayapó", ${ }^{4}$ através da breve notícia que dá o sertanista Antônio Pires de Campos em

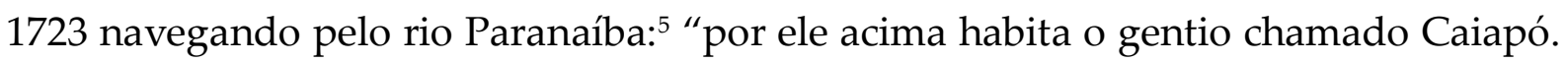
Este gentio é de aldeias, e povoa muita terra por ser muita gente, cada aldeia com seu cacique" (CAMPOS, 1976, p. 181).

\footnotetext{
2 "Segundo referem os descendentes de Bartholomeu Bueno, o appellido de Anhangoera (diabo velho) fora-lhe dado pelos índios por seus estratagemas e manhas, sendo entre estes o de em sua presença fazer arder a aguardente com applicação da luz". (OLIVEIRA, 1973 p. 496)

${ }^{3}$ Futura Vila Boa, capital da capitania de Goiás.

${ }^{4}$ Ao longo do artigo este termo aparecerá com a letra C entre aspas: "Cayapó"; como também com a letra K sem aspas: Kayapó. O primeiro é o seu modo de aparição na documentação histórica, e o segundo é a normatização da ABA (Associação Brasileira de Antropologia), sendo utilizado na Etnografia.

${ }^{5} \mathrm{Na}$ atual divisa dos estados de Minas Gerais com Goiás.
} 
O nome Kayapó deriva da língua Tupi, isso se deve ao fato de que os intérpretes responsáveis pelo contato foram de origem Tupi ou Guarani escravizados pelos paulistas, como também ter sido o nheengatu a língua geral falada nas estradas pelos bandeirantes desde o século XVI, tendo como significado, literalmente, "como macaco" (TURNER, 1992), ou seja, "selvagem", "não-humano" etc. Dessa forma, “o termo Kayapó é uma designação genérica que não corresponde a uma etnotaxonomia social" (MANO, 2015, p. 60), estando diretamente relacionado com a dicotomia entre Tupi e Tapuia.

A antinomia entre "sertão" e litoral7 foi um dos fatores da oposição entre Tupis e Tapuias. ${ }^{8} \mathrm{O}$ termo Tapuia não está associado a nenhum grupo indígena, na verdade, assim como a maioria das sentenças históricas para se referir aos silvícolas, trata-se de uma exonímia. John Monteiro (2001), ao discutir a obra de Gabriel Soares de Souza, mostra que os escritores coloniais projetavam os grupos Tapuias como a antítese da sociedade tupinambá, descrevendo-os quase sempre em termos negativos, visto que seus informantes eram tupis aldeados. Dessa forma, os Tapuias eram vistos como inimigos dos Tupis, o que acabou sendo apropriado pelos europeus, principalmente pelo fato dos primeiros se negarem a aceitar o avanço da colonização, o batismo e a catequese, reagindo com guerras, fugas e assassinatos, habitarem os "sertões" e falarem uma língua travada. "De fato, a denominação 'Tapuia' aplicava-se frequentemente a grupos que - além de diferenciados

\footnotetext{
6 "Sertão" encontra-se entre aspas em razão de que o termo não faz referência a um dado de realidade empírica, não está associado a uma região geográfica, mas sim ao imaginário, a uma representação construída socialmente e culturalmente. Para mais informações ver (AMADO, 1995; AMANTINO, 2008).

${ }^{7}$ Seus significados são complementares. Sem a noção de "litoral" = "manso", não haveria a noção de "sertão" = "hostil", e vice-versa.

8 Esta analogia de Tupi = litoral, Tapuia = sertão, foi utilizada como justificativa do avanço colonial para o interior do Brasil, visto que o litoral representava a vida "civilizada" e o "sertão" a vida selvagem. Entretanto, estudos históricos, etnológicos e arqueológicos (BROCHADO, 1980; LARAIA, 1986) já mostraram que grupos Tupi habitavam praticamente todo o território brasileiro (principalmente áreas tropicais e subtropicais), inclusive os "sertões", bem como vários grupos denominados Tapuias habitaram o litoral.
} 
socialmente do padrão tupi - eram pouco conhecidos dos europeus" (MONTEIRO, 1994, p. 19). Por serem representados como a antítese dos Tupi (manso), foram retratados como selvagens e incivilizados.

A visão negativa atribuída aos Tapuias remonta de meados do século XVI, pois desde o primeiro contato entre portugueses e indígenas os Tupis começaram a ser contatados, assim como aponta John Monteiro:

De fato, com frequência os inimigos mais indicados para uma guerra justa foram os chamados Tapuia, e mesmo a lei de 1570 cita nominalmente os Aimoré - denominação que incluía diversos povos jê que resistiam arduamente aos avanços portugueses no litoral da Bahia. Desde cedo, no entanto, os colonos manifestaram clara preferência por cativos tupi e guarani, e isto por diversos motivos: a maior densidade demográfica, a facilidade de comunicação através de uma "língua geral" e a maior possibilidade de formar alianças; mediante estes contatos, novos cativos justificavam seu interesse. (1994, p. 52)

Essa dicotomia imposta pelo olhar estrangeiro definiu modelos representativos e classificatórios dos grupos indígenas como mansos e hostis, respectivamente propensos a civilização e incivilizados, falantes de uma língua geral e de uma língua travada (MANO, 2006). Em nenhum caso esses grupos foram vistos em seus próprios termos. Os Tapuia, "caracterizados como inimigos ao invés de aliados, representavam, em síntese, o traiçoeiro selvagem dos sertões que atrapalhava o avanço da civilização, ao invés do nobre guerreiro que fez pacto de paz e de sangue com o colonizador" (MONTEIRO, 2001, p. 174). Assim, os modelos criados deram suporte para a investida de uma guerra justa ${ }^{9}$ contra esses grupos, que por não se tratar do foco principal desse artigo, não será aqui discorrido, ${ }^{10}$ entretanto é possível aferir que tanto para os indígenas como para os não-índios, as políticas de guerra eram orientadas por seus respectivos sistemas práticos e simbólicos, simultaneamente mitológicos, econômicos, sociais, políticos, entre outros. Em virtude

\footnotetext{
${ }^{9}$ Ver (FREITAS, 2014).

${ }^{10}$ Para informações sobre a guerra entre agentes coloniais e os "Cayapó" ver (ASNIS, 2018; ATAÍDES, 1998; GIRALDIN, 1994, 2001; JUNQUEIRA, 2017; MANO, 2011, 2012; MORI, 2015).
} 
disso, no ano de 1730 o então governador da capitania de São Paulo, Antônio da Silva Caldeira Pimentel, permite a guerra contra todas as nações de "gentios" que cercavam o rio Grande, dando início a um violento combate na região do norte de São Paulo, Triângulo Mineiro, sul de Goiás e leste do Mato Grosso do Sul, durando aproximadamente 40 anos, até que novas políticas indígenas e indigenistas passaram a entrar em vigor.

\section{Diretório Pombalino e a busca pela "paz"}

Essa nova ${ }^{11}$ busca em modificar as relações entre índios e não-índios se deu a partir da década de 1750, quando surge o Diretório pombalino de Sebastião José de Carvalho e Melo, o Marquês de Pombal, secretário de Estado durante o reinado de D. José I, rei de Portugal. O Diretório, criado no ano de 1755 e já aplicado na região amazônica, instaurou um novo modelo para a política indigenista colonial e passou a valer em 1758 para todo o Brasil, incluindo Goiás, muito em virtude dos insucessos das investidas de guerra contra as populações indígenas durante quase todo o século XVIII. Os principais pontos estabelecidos pelo Diretório eram, de acordo com Anderson Batista de Melo (2008, p. 87) e Marivone Matos Chaim (1983, p. 135-138), a introdução da língua portuguesa em detrimento das línguas nativas e língua geral; escolha de nomes e sobrenomes lusitanos para os "gentios"; proibição da punição a casamentos mistos; organização urbana dos aldeamentos semelhantes ao modelo europeu; 12 reconhecimento de súdito do rei de Portugal ao "gentio" devidamente cristianizado; incentivo à lavoura e ao comércio; proibição de referir-se aos indígenas

\footnotetext{
${ }^{11}$ Nova, pois, antes do Diretório, havia o Regimento das Missões, que norteava a política de aldeamentos na colônia (ALMEIDA, 2010).

${ }^{12}$ Segundo Luís Augusto Bustamante Lourenço, "Os aldeamentos indígenas criados pelo Estado colonial não se assemelhavam a núcleos pré-urbanos, mas a aldeias no sentido europeu, ou seja, habitats rurais concentrados. O termo aldeia era usado em Portugal para designar aglomerados camponeses, equivalente ao villagio italiano ou à village francesa. No Brasil, os colonizadores passaram a designar de aldeias, indistintamente, tanto as tabas indígenas, isto é, os aglomerados pré-coloniais, quanto os aldeamentos, núcleos de reclusão indígena compulsório. O rótulo de aldeia seria uma forma de caracterizar a inferioridade do aglomerado indígena, associando-o ao rural, portanto inferior aos arraias e vilas: esses teriam caráter urbano, mesmo se tratando de aglomerações extremamente modestas" (2015, p. 33)
} 
utilizando a alcunha de "negro"; 13 que postos públicos e honoríficos poderiam ser delegados aos indígenas; e persuasão do uso de vestimentas.

Um de seus principais objetivos era o de povoar o território de Goiás pelos próprios indígenas, transformando-os em vassalos e partes de um projeto de ocupação através de sua redução "pacífica" propiciada pela construção dos aldeamentos. Dessa maneira, o Diretório estaria inserido, também, em uma moral econômica de Portugal na qual o indígena tornava-se força de trabalho dos interesses coloniais, além de garantir mais efetivamente a ocupação do poder português em terras brasileiras. Segundo Chaim, “Pombal objetivava transformá-los em cidadãos ativos na tarefa de povoamento, através da sua integração na comunidade" (1983, p. 76).

Isso porque, com a queda do número das auríferas de ouro e a consequente crise em que entrava a Capitania de Goiás, outros meios de mantê-la economicamente ativa tiveram que ser aplicados, entre eles, a agropecuária, daí a necessidade de mais mão-de-obra, já que se tornava difícil a importação de escravos africanos em virtude desta crise. Segundo Ossami de Moura (2006, p. 33), em 1755 a mineração em Goiás começa a entrar em fase de decadência, agravando-se a partir de 1780. Em carta datada de 29 de dezembro de 1784, o então governador Tristão da Cunha Menezes diz:

\begin{abstract}
A abundancia d'ouro que nos principios desta Capitania appareceu pelas partes do Norte; as esperanças de novos descobertos; a commodidade de poderem os moradores daquellas partes fundir as suas respectivas parcellas, sem passar pelo incommodo de o hir fazer quazi cem legoas desta Capitania por caminhos naquelle tempo infestados, forão os motivos de se erigir e estabelecer no Arrayal de São Felix huma casa de Fundição: Porem a falta geral que hoje se experimenta dos mesmos descobertos e as poucas forças que ha para extrahir das partes ja conhecidas o pouco ouro que ellas offerecem, tem dalguma forma tornado inutil e effeito desnecessario esta sabia e então bem acertada providencia. (R.IHGB, TOMO 84, p. 164)
\end{abstract}

13 Sobre o uso do termo "negro" para as populações indígenas, ver (MONTEIRO, 1994). 
O naturalista Johann Emanuel Pohl faz um pequeno resumo em sua obra "Viagem no interior do Brasil" (1951, p. 341), mostrando a decadência das lavras de ouro e o declínio da extração na capitania de Goiás dos anos de 1788 até 1819, evidenciando a crise que Goiás estava enfrentando. De acordo com Batista de Melo os "povos indígenas não eram, para esse novo espírito, um entrevero que deveria ser eliminado ou expulso das áreas de interesse econômico e territorial, da metrópole. Os índios eram agora parte imprescindível das necessidades do engenho colonizador" ( 2008, p. 96).

É nesse contexto que, a partir de 1750, os reformadores pombalinos começam a enviar diretores para as aldeias a fim de incentivar os indígenas a praticar a agricultura, a coleta de frutos e o comércio nas cidades. Entretanto, em virtude da resistência ao trabalho forçado, as contínuas fugas e ataques aos colonos, o Diretório não obteve sucesso em Goiás até a década de 1770 com o governo de José de Vasconcelos Soveral Carvalho, o futuro barão de Mossâmedes, e os governadores, nesse período (1758-1770), continuaram autorizando a organização de expedições para se fazer guerra aos "gentios que infestavam a capitania". "Mas a guerra não resolvia um dos principais objetivos do Diretório, que era transformar os índios em agricultores sedentários" (KARASCH, 1992, p. 398). ${ }^{14}$

Dessa forma, de acordo com Chaim (1983), Pombal, contrário aos jesuítas, que defendiam o índio como segregado, objetivava integrá-los na comunidade, transformando-os em sujeitos ativos na tarefa de povoamento, como queria a Metrópole. Mas para alcançar tais objetivos deveria haver um convívio "pacífico" com os colonizadores, dado através da catequese e dos aldeamentos, visto que, de acordo com Chaim, “até o início da política pombalina para o Brasil (1750), em Goiás como no restante do país, o relacionamento entre o colonizador e o índio pautou-se

\footnotetext{
${ }^{14}$ É importante frisar que essa guerra destacada pela autora se refere ao confronto físico, pois a própria ideia de "pacificação", como veremos, nada mais é do que uma extensão e redefinição da própria guerra, porém, feita de outra maneira, mas não menos violenta.
} 
pelas hostilidades mútuas, face às quais as leis tornavam-se sem efeito" (1983, p. 75). ${ }^{15}$

Assim sendo, a responsabilidade administrativa dos aldeados, que antes pertencia aos jesuítas, passa para as mãos dos diretores e estes seriam escolhidos pelo capitão-geral da capitania.

O aporte legal pombalino proibiu o trabalho compulsório indígena e retirava da Companhia de Jesus o controle dos aldeamentos, passando-o aos diretores funcionários do Estado. Os aldeamentos eram povoações que, desde o século XVI eram formados para concentrar, por motivos variados, as populações indígenas. Agora, seriam utilizados como instrumentos governativos. (BATISTA DE MELO, 2008, p. 86)

A essas mudanças na organização dos aldeamentos correspondiam igualmente mudanças nas relações com os povos indígenas, pois se antes do Diretório o objetivo principal era concentrar diferentes grupos indígenas em um mesmo local para a realização da cristianização e "civilização" pelos jesuítas, após o Diretório, e particularmente em Goiás, sua finalidade foi a de

desocupar as terras indígenas para a expansão mineral e das atividades agropastoris; a sedentarização, cristianização e civilização dos indígenas para uma melhor integração à sociedade colonial; e a implantação de núcleos populacionais, visando a sua transformação em centros urbanos. (OSSAMI DE MOURA, 2006, p. 32)

Segundo Ossami de Moura (2006), o processo de construção dos aldeamentos na região de Goiás se dividiu em dois períodos. ${ }^{16}$ Mas, como aqui o foco são os

\footnotetext{
${ }_{15}$ A autora parece considerar somente os objetivos instituídos pelo Diretório e não sua realidade, afinal as hostilidades entre indígenas e colonizadores não se encerraram com o advento das legislações pombalinas, muito pelo contrário, como é mostrado ao longo do artigo, os confrontos, as guerras, os assassinatos, as destruições de aldeias, entre outros, continuaram, muitas vezes com uma maior intensidade do que anteriormente.

16 "O primeiro deles deu-se a partir de 1741, em plena vigência da sacra auri fames e com o florescimento febril dos povoados. Nesse período, a preocupação da população regional e da Coroa estava centrada na extração do ouro. Já o segundo período teve início em 1755 [...]" (OSSAMI DE 
aldeamentos do Diretório porque foram neles que grupos "Cayapó" negociaram sua "pacificação", o recorte temporal é a partir de 1755, quando a mineração começa a entrar em fase de decadência, agravando-se a partir de 1780, dando início a consolidação de um novo ciclo econômico da capitania: a agropecuária. Nessa segunda fase foram construídos em Goiás os dois aldeamentos focos desse artigo, São José de Mossâmedes (1775), localizado a 5 léguas de Vila Boa para os Akroá e posteriormente recebendo os Xavante, Krajá, Javaé, “Cayapó”, Carijó, Naudoz e Xacriabá; e Maria I (1781), construído a 13 léguas a sudoeste de Vila Boa, às margens do rio Fartura, para os "Cayapó".

Nessa segunda fase, de acordo com Karasch (1992), a política indigenista em Goiás tinha a pretensão de livrar a capitania dos índios não assimilados e concomitantemente trazê-los para debaixo da autoridade da Igreja e do Estado como leais vassalos da monarquia portuguesa. Mas enquanto as autoridades lusitanas buscavam a cristianização e a civilização indígena para convencê-los a aceitar o aldeamento, as milícias, as bandeiras e os colonos armados procuravam "desinfestar" a capitania, escravizando as mulheres e os filhos. ${ }^{17}$ Dessa forma, como aponta a autora, quaisquer que fossem as diretrizes de Lisboa, a busca de riquezas minerais, fazendas e escravos indígenas, orientava a política indigenista, causando uma violenta resistência ou fuga ${ }^{18}$ dos atacados e escravizados.

Isso mostra que este meio de "pacificação" não promoveu, como aponta Batista de Melo, “uma normalidade e tranquilidade antes inexistentes" (2008, p. 97), segundo Lourenço,

MOURA, 2006, p. 33). Trabalhos mais recentes apontam o ano de 1748 como a data de fundação do primeiro aldeamento colonial em Goiás - quando esse ainda pertencia a São Paulo (MORI, 2015; NASCIMENTO, 2019).

${ }_{17}$ Claramente o choque entre estruturas da prática e práticas das estruturas.

18 Ossami de Moura (2006) também aponta que as fugas estariam relacionadas aos termos da dizimação e dos maus-tratos que os indígenas recebiam, porém, essa visão desconsidera os agenciamentos por parte dos próprios indígenas, afinal, fugiam não somente pelas ações dos nãoíndios, mas também por seus próprios interesses. 
a aplicação das medidas do Diretório não fez amenizar, mas sim piorar a situação dos índios dos aldeamentos. Os homens nomeados como diretores estavam, em sua maioria, ligados aos interesses dos fazendeiros locais e não às intenções da Coroa. Sem o controle e a ação moderadora dos jesuítas, viam-se desimpedidos para a prática sistemática da escravidão indígena. A permissão de que brancos se estabelecessem em terras indígenas incentivou a violência e a expulsão de índios em áreas sob jurisdição dos aldeamentos. As rebeliões indígenas ocorridas no período da vigência do Diretório atestam o nível de maus-tratos a que as populações estavam sendo submetidas. Por exemplo, em 1755, ocorreu uma rebelião acroáxacriabá nos aldeamentos do Duro e Formiga. Apesar de o governador de Goiás José de Almeida Vasconcelos, Barão de Mossâmedes, ter tentado estabelecer as diretrizes pombalinas para os aldeamentos em 1771, teve de ceder às pressões dos fazendeiros que queriam manter a escravidão indígena, pois a decadência do ouro empobrecia a capitania e tornava difícil a importação de escravos africanos. $(2015$, p. 32)

Os próprios grupos indígenas assimilados do norte da capitania (possivelmente Xavantes e Acroás) estavam requerendo missionários para os serviços religiosos em suas comunidades, além de proteção contra a escravidão que sofriam por parte dos colonos e fazendeiros da região (KARASCH, 1992, p. 398). Isso nos mostra a dupla face da política indigenista em Goiás (a da legislação pombalina e a dos poderes locais), tanto quanto a política (dos) indígena(s) em face da política indigenista.

Foi no governo do Barão de Mossâmedes (1772-1778) que teve início em Goiás o processo de integrar os índios ao sistema pombalino. Ele foi o responsável por colocar o Diretório em prática ao criar o aldeamento de Nova Beira (1775), no norte da capitania, para abrigar os Karajá e Javaé e o aldeamento de São José de Mossâmedes (1775) com o objetivo de servir de modelo aos demais.

Com os contínuos ataques principalmente dos "Cayapó" e Xavantes e a situação não resolvida nas fronteiras goianas, no dia primeiro de outubro de 1771, Martinho de Mello e Castro, diplomata e político português responsável por 
reformar o sistema colonial de Portugal, enviou uma carta para o então governador de Goiás, José de Almeida Vasconcelos (Barão de Mossâmedes), dizendo que os territórios "vazios"19 da capitania deveriam ser ocupados pelos próprios "nacionais", ou seja, pelos indígenas, ${ }^{20}$ insistindo que sua civilização era o objetivo mais importante a se fazer naquele momento, aconselhando as autoridades a ganhar a confiança dos índios por meios de suavidade e brandura., "fazendo-lhes presentes para os atrair, dando-lhes os gêneros que mais os agradavam em troca dos que traziam do sertão e deixando-os voltar para as suas habitações sossegados, seguros e contentes, até virem por suas livres vontades" (CHAIM, 1983, p. 399).

Em virtude dessas Instruções, pode-se imaginar que o barão de Mossâmedes foi o administrador que melhor geriu o sistema de aldeamentos de acordo com o Diretório Pombalino, tendo como meta a "pacificação" dos indígenas através da persuasão. Entretanto, como aponta Cancelier Dias (2017, p. 42), durante seu governo houve a destruição de uma aldeia "Cayapó" e uma Xacriabá, ocasionando centenas de mortos e prisioneiros. Seu mais importante projeto, o aldeamento de São José de Mossâmedes, chegou a abrigar mais de 8000 habitantes, dando início à época dos aldeamentos em Goiás a partir dos princípios estabelecidos pelo Marquês de Pombal. E a partir desse momento, no final do século XVIII, as mudanças na política indigenista em Goiás parecem coincidir com mudanças na política dos indígenas. Se antes suas estratégias de contatos eram quase que invariavelmente guerreiras, essa prática da estrutura coloca-se em relação à uma estrutura da prática na qual passaram a coexistir diferentes estratégias. Não só uma clara redefinição da guerra como também alternativas de negociação de aldeamento, fugas, burlas e continuidade dos ataques.

\footnotetext{
${ }^{19}$ Entendido como ausente da presença portuguesa.

${ }^{20}$ Esses espaços já eram ocupados pelos índios, porém, eram aqueles considerados bárbaros e selvagens. A ocupação deveria ser realizada por aqueles que já estivessem cristianizados e "civilizados".
} 


\section{A realidade da "pacificação" nos aldeamentos de Maria I (1781) e São José de} Mossâmedes (1775)

No ano de 1780 foi formada uma bandeira composta por 26 índios Bororo, 12 soldados Pedestres, 12 índios Acroá e provavelmente 3 intérpretes ou línguas ${ }^{21}$ da nação "Cayapó" - a mando do então governador de Goiás Luís da Cunha Menezes e comandada por um soldado Pedestre da Capitania, de nome José Luís Pereira (CHAIM, 1983, p. 124; SAINT-HILAIRE, 1975, p. 63; R.IHGB, TOMO 84, p. 135), o qual já havia tomado parte em várias expedições contra os índios e agora se encarregava de subjugar os "Cayapó" (tidos até então como "indomáveis"), sob a proteção do Capitão-geral - com o intuito de cercar uma aldeia "Cayapó" e persuadilos a aceitar o aldeamento. “Essa tentativa de atrair os Kayapó do sul para um aldeamento era visto pelo governador de Goiás, como uma maneira eficiente de cessar as hostilidades entre índios e não-índios e expandir o controle da capitania" (MORI, 2015, p. 123).

Partiram no dia 15 de março de 1780 (R.IHGB, TOMO 84, p. 139), ${ }^{22}$ embrenhando-se em território indígena. Após vários meses percorrendo os "sertões" da capitania e aproximando-se com sinais de amizade com todos os "Cayapó" que encontravam, graças à ajuda dos três línguas, foi se estabelecendo um contato entre os sertanistas e os indígenas, sendo esses, tratados com "bondade" e presenteados a fim de convencê-los a acompanhar a bandeira até Vila Boa para conhecer o governador Luís da Cunha Menezes. Persuadidos, no dia 21 de setembro do mesmo ano, tendo-se passado 6 meses e 6 dias desde que a expedição saiu, um grupo de cerca de quarenta pessoas, composto por um velho de nome Romexi, seis guerreiros, mulheres e crianças, adentraram, junto ao soldado Luís e toda sua tropa, na capital da capitania de Goiás.

${ }^{21}$ Para mais informações sobre os línguas ver (CANCELIER DIAS, 2017).

${ }^{22}$ Correspondência do governador Luís da Cunha Meneses ao Sr. Martinho de Melo e Castro, 1781. 
A recepção foi calorosa e realizada na casa do governador com a maior pompa possível de acordo com o próprio Luís da Cunha Menezes (R.IHGB, TOMO 84, p. 139). ${ }^{23}$ Uma grande festa foi organizada; tiros de canhão foram disparados; a artilharia e mosquetaria se apresentaram; e na Igreja Matriz foi realizada uma missa na qual foi cantada Te Deum. Além disso, de acordo com a documentação, uma senhora "Cayapó" que havia saído doente da sua aldeia e estava prestes a morrer foi batizada e sepultada na Igreja Matriz.

Após a grande recepção, os "Cayapó" permaneceram na capital e no aldeamento de São José de Mossâmedes por aproximadamente 25 dias. Depois foram mandados de volta para suas aldeias carregando presentes a fim de atrair suas nações, demonstrando o sucesso que a amizade com Sua Majestade poderia proporcionar. Foi então que no dia 16 de outubro de 1780 saíram da capital todos os "Cayapó" e no dia 10 de maio de 1781237 índios "Cayapó" de ambos os sexos e diferentes idades entraram em Vila Boa liderados pelo maioral Angrahyochá e o cacique Xaquenonau (ALENCASTRE, 1864, p. 315), recebendo uma recepção semelhante à dos primeiros. Em junho do mesmo ano, 113 crianças foram batizadas por meio da graça do Reverendo Parocho da Igreja Matriz e mais 6 que haviam nascido na capital.

Com este contingente de grupos pertencentes aos Jê meridionais adentrando a capitania, o governador mandou construir para todos eles, a $11^{24}$ léguas de Vila Boa (SAINT-HILAIRE, 1975, p. 63), um aldeamento que recebeu o nome de Maria I, ${ }^{25} \mathrm{em}$ homenagem a rainha de Portugal D. Maria I. ${ }^{26}$ Logo em seguida de sua construção,

\footnotetext{
${ }^{23}$ Idem.

${ }^{24}$ Raymundo José da Cunha Mattos diz que Maria I se encontrava a 13 léguas a sudoeste de Vila Boa, na margem esquerda do ribeirão da Fartura, pouco distante da serra Dourada (1979, p. 42).

${ }^{25}$ O aldeamento de Maria I viria a ser extinto no ano de 1813, em decorrência da má administração do aldeamento, das constantes fugas por parte dos "Cayapó", da superlotação e dos interesses indígenas. Aqueles que permaneceram no aldeamento foram transferidos para São José de Mossâmedes.

26 "Aldeia Maria a Primeira, por ser a primeira que se conseguio estabelecer-se da referida Nação Cayapó como a V. Ex. ${ }^{a}$ ja communiquei em carta de 20 de Julho deste prezente anno" (R.IHGB, TOMO 
“cerca de 600 índios Kayapó foram abrigados na aldeia Maria I, deixando de constituir perigo às caravanas que transitavam pela estrada de São Paulo" (CHAIM, 1983, p. 124). Tal informação não condiz com a documentação histórica, o próprio governador de Goiás, Tristão da Cunha Menezes, sucessor e irmão de Luís da Cunha Menezes, presenciou um ataque realizado pelo último grupo "Cayapó" aldeado em Maria I, desmitificando a ideia de que esses indígenas estariam agora pacificados, bem como a de que a capitania de Goiás estaria passando por um período de total tranquilidade. Chaim, ao mencionar que os "Cayapó" deixaram de constituir perigo às caravanas a partir do momento em que foram aldeados, acaba interpretando a história desses grupos como uma linha reta: da guerra à paz, o que não se sustenta ao fazer a análise minuciosa dos dados empíricos, afinal, a transformação da política de guerra em política de "pacificação" faz dessa, também, um modo de reprodução da própria política de guerra, porém realizada de maneiras diferentes.

O ponto mais importante sobre a construção deste aldeamento está na passagem descrita por Luís da Cunha Menezes no que se refere a escolha do local:

os mandei aldear no sitio que elles mesmos escolherão distante desta Capital para a parte do Sul 11 legoas, na margem do rio chamado dos Índios abundantissimo de peixe, que é huma das adições não pequena para ajuda da subsistência, de estabelecimentos semelhantes. (R.IHGB, TOMO 84, p. 141) ${ }^{27}$

Esta decisão tomada pelos próprios indígenas mostra que, mesmo concordando em serem aldeados e assentindo em viver sob certas condições impostas pelos não-índios, os "Cayapó" criaram mecanismos que permitiram a eles expressar seus anseios (MORI, 2015, p. 125), colocando-os no patamar de protagonistas históricos, afinal, negociavam, de alguma maneira, sua participação no

84, p. 145).

${ }^{27}$ Correspondência do governador Luís da Cunha Meneses ao Sr. Martinho de Melo e Castro, 1781. 
projeto dos aldeamentos, possibilitando a permanência de algumas formas ou traços culturais indígenas. Segundo Giraldin,

deve ter havido algum tipo de negociação entre o governador e as lideranças Cayapó, pois foram eles que escolheram o local para o novo aldeamento: ficava nas margens do riacho chamado Fartura, próximo dos rios Claro e Pilões. Com isso, poderiam permanecer em uma região com as mesmas características ambientais das áreas de suas aldeias. (1994, p. 99)

Tal agenciamento indígena mostra que esses grupos estavam inseridos nos jogos de interesses, passaram agora a agenciar com a alteridade e não somente a aceitar o que vinha de fora. Para Bhabha: "É na emergência dos interstícios - a sobreposição e o deslocamento de domínios da diferença - que as experiências intersubjetivas e coletivas de nação [nationes], o interesse comunitário ou o valor cultural são negociados" (1998, p. 20). Assim sendo, a guerra física, que vinha sendo praticada estruturalmente desde o primeiro contato, passa a se tornar insustentável para os grupos "Cayapó", levando-os a negociar o aldeamento, ressignificando seus sistemas práticos e simbólicos.

Eis que surge um questionamento. Durante toda a documentação histórica observamos que os aldeamentos foram construídos como forma de apaziguar as populações indígenas, mas e se, ao contrário, a aceitação dos índios em serem aldeados não estaria diretamente relacionada com a pacificação dos não-índios? E se essas populações não estavam agenciando os colonizadores para que interrompessem as matanças que vinham causando? Segundo Marcel Mano (2011), as relações com o mundo exterior "Cayapó” (JUNQUEIRA, 2017; MANO, 2012) se mantiveram, em certo aspecto. Embora mudassem ou transformassem as modalidades de contato, guerra e paz em si não importavam, senão como meios pelos quais as relações fins estariam presentes na aquisição da cultura material do não-índio. O que acontece é que se antes tais aquisições se davam através de 
conflitos, logo, da guerra, "agora eles tratavam de consegui-lo por meio de trocas comerciais, embora às vezes bastante desvantajosas" (MANO, 2011, p. 205). De guerreiros a comerciantes (pois negociavam suas formas de inserção nos aldeamentos), a "transformação cultural - migração, diáspora, deslocamento, relocação - torna o processo de tradução cultural uma forma complexa de significação" (BHABHA, 1998, p. 241). Tanto a guerra como a "paz", para os indígenas, eram formas deles se apropriarem do mundo exterior, sendo o mesmo para os agentes coloniais.

Assim sendo, embora extremamente desvantajosas e arriscadas, as trocas comerciais possibilitavam aos Kayapó o afluxo de bens que antes eles só conseguiam mediante o roubo. Pedir coisas e dar outras, exigir mercadorias para apaziguar os ânimos, tratar relações e vender outros índios por objetos cujo processo de produção os mesmos desconheciam, fez da paz não uma ruptura, mas um prolongamento da guerra. Ou em outros termos, estabelecer a paz foi estratégia de continuar a guerra por outros meios (MANO, 2011, p. 206)

Ruptura e continuidade não devem, assim, ser analisadas como polos distintos no processo histórico, há imbricamentos entre elas e é possível observar isso, como por exemplo, no roubo das armas nos aldeamentos tanto de Maria I como de São José de Mossâmedes, em que os "Cayapó" aprendiam a manejá-las, com a ajuda dos nãoíndios e retornavam para suas aldeias carregando o armamento, distribuindo entre seus iguais e voltando a atacar os moradores da região, agora com o mesmo instrumento que antes lhes "causava medo", como destacado por Joaquim Norberto Sousa e Silva:

sem temor dos homens que outr'ora tinham por deuses, e manejando tambem como elles os terríveis trovões. Assim continuavam a ser o terror dos habitantes pacificos, que surprehendidos por suas correrias, viam roubadas e incendiadas as suas casas e pagavam com a vida e defeza de seus haveres. (SOUSA E SILVA, 1973, p. 529) 
Outro ponto chave é de que o intuito maior dos aldeamentos era cristianizar os indígenas para pacificá-los, mas os dados empíricos mostram que na realidade não era o que estava acontecendo. “Era por Lei função dos agentes da Coroa extirpar o paganismo dos índios, a sua permanência após anos de aldeamento notava tolerância, negociação e conflito entre os agentes coloniais e índios" (CANCELIER DIAS, 2017, p. 275). ${ }^{28}$ Tanto foi assim que uma das exigências do Diretório, a realização dos casamentos indígenas aos moldes do cristianismo, pregando a monogamia, não se cumpriu de fato na prática. De acordo com os cronistas, nos aldeamentos "os casamentos são celebrados com um grande banquete e com danças, durante as quais a recém-casada segura uma corda amarrada à cabeça do marido costume simbólico que não necessita de maiores explicações" (SAINT-HILAIRE, 1975, p. 71). Além disso, mesmo a monogamia sendo "confirmada" por Pohl: "Em estado selvagem, vivem em poligamia, o que, naturalmente, não acontece na aldeia" (1951, p. 363), Cancelier Dias (2017) afirma que é difícil acreditar em tal passagem, utilizando uma citação do governador Luís da Cunha Meneses em Maria I, que diz:

[...] certa bebida que eles fazem de milho pisado e azedado, de molho em água, a que chamam chicha [sic] e depois de todos bêbados e em confusão da mesma bebedice, sem se diferençarem tanto eles como elas, usam de toda a ilícita liberdade, sem atenderem a união de parentesco, mostrando nisto que só obrigados da falta de conhecimentos é que se poderão cometer semelhante e repugnante delitos. (APARÍCIO, 1998, p. 373)

Ora, se em Maria I assim ocorria, dificilmente em São José de Mossâmedes tal prática havia sido extirpada, já que diversos outros rituais, cerimônias, costumes e crenças se mantiveram: "as fronteiras podem persistir apesar do que podemos, metaforicamente, denominar 'osmose' das pessoas que as atravessam" (BARTH, 1998, p. 204). Não só se mantiveram como também misturaram elementos coloniais com suas tradições e conviveram com princípios cristãos, e não necessariamente de

\footnotetext{
28 Permanência de rituais considerados pagãos.
} 
forma pacífica, "porque uma vez um padre fôra assassinado, no altar, pelos índios" (POHL, 1951, p. 361), obrigando os soldados de São José a utilizarem espingardas nas missas de domingo e nos dias santos. Em contrapartida "apreciam muito as festas de igreja e pedem sempre que se lhes permita assistirem às que se realizam em Goiás" (POHL, 1951, p. 107), mesmo não possuindo a menor ideia do que é o cristianismo enquanto religião e nem saberem rezar o pai nosso (lembrando que todos eram batizados). A morte desse padre reflete muito bem como todas as ações dos "Cayapó" eram formas de agenciamento, eram maneiras de se fazer política.

Culturas que medeiam o convencional de modo dialético fazem da diferenciação (o que inclui as qualidades do paradoxo, da contradição e da interação recíproca) a base de seu pensamento e de sua ação. Elas encenam as contradições dialéticas e motivacionais de modo consciente em sua administração dos papéis, rituais e situações, e assim reconstituem continuamente o convencional. (WAGNER, 2012, p. 274-275)

Observa-se que os aldeamentos eram palcos de intensas negociações, rearranjos, ressignificações, interesses objetivos e subjetivos, rupturas e continuidades. $\mathrm{O}$ fato de estarem aldeados não os colocou em uma submissão aos agentes coloniais, muito pelo contrário, cremos que muito possivelmente esses agentes eram muito mais submissos aos indígenas, pois dependiam de sua mão-deobra e, por isso, não podiam interferir tanto em seus moldes de vida, em seus manejos de mundo, caso contrário eles poderiam facilmente fugir para além das fronteiras, como é o caso ocorrido no dia 6 de janeiro de 1784 em que o sargento regente de Maria I apresenta ao governador Luís da Cunha Meneses sua desconfiança com relação aos índios, que devido à pouca guarnição no aldeamento, têm demonstrado desrespeito e desobediência, destemendo até mesmo as forças que os contêm, evidenciando que enquanto as demandas dos "Cayapó" estavam sendo atendidas, eles permaneciam em "paz", mas quando faltava-lhes guarnições, se rebelavam, o que claramente demonstra um certo controle por parte desses grupos 
em obedecer quando fossem atendidas suas exigências e desobedecer quando não fossem.

Chega-se, assim, ao entendimento de que se para os agentes coloniais a "pacificação" significava civilizar e incluir (OLIVEIRA, 2016), para os indígenas ela tinha como significado a possibilidade de continuarem a se apropriar dos bens materiais dos não-índios. Se a análise sobre os aldeamentos permite averiguar a política indigenista de utilizar a "paz" como pressuposto para os interesses coloniais, ou seja, transformar o outro em súdito, mão-de-obra e adepto ao modelo cultural europeu imposto, o inverso, tal seja, a política indígena, tinha a pretensão de apropriar o universo simbólico dos não-índios de uma forma diferente daquela instituída pela prática da estrutura, ou seja, a guerra. A "paz" parecia ser uma forma estratégica mais eficaz de assegurar os interesses e agenciamentos dos "Cayapó", por mais que ela tenha sido, em diversos momentos, ineficaz, obrigando esses grupos a voltar a realizar ataques e causar mortes aos seus inimigos, que por ventura se tornavam aliados dependendo das situações pragmáticas em que as alteridades se encontravam.

\section{O significado da "pacificação"}

O que se buscou contemplar nesse artigo foi como o conceito da "pacificação", contextualizado no recorte histórico temporal de meados do século XVIII e início do XIX na região que abrange os atuais norte de São Paulo, Triângulo Mineiro, sul de Goiás e leste do Mato Grosso do Sul, foi apropriado pelos agentes de um processo de colonização dos "sertões" brasileiros e pelos povos indígenas que ali habitavam, focando na política indigenista estabelecida pelo Diretório Pombalino através da construção dos aldeamentos de Maria I e São José de Mossâmedes e sua recepção pelos grupos historicamente denominados "Cayapó".

Pudemos averiguar que: 
A qualificação de "pacificados" só reflete o ponto de vista dos colonizadores, mas nada diz sobre o modo como ocorre a recepção e a utilização de tal ordenamento pelos nativos. A aplicação desta categoria administrativa, de natureza puramente policial-militar, a descrições históricos constitui um crasso erro, sendo ainda pior quando dela se pretende inferir implicações socioculturais. (OLIVEIRA, 2008, p. 30)

Ou seja, a categoria de "pacificação" deve ser compreendida através de seus diferentes usos em seus mais diversos contextos históricos atrelada aos interesses dos agentes que a utilizam e a utilizaram. “No período colonial, a 'pacificação' foi pensada inicialmente como uma atividade bélica, mas, logo em seguida, ingressou em uma fase pedagógica e protetora" (OLIVEIRA, 2016, p. 346), sendo exatamente isso o observado a partir das políticas dos aldeamentos. Até o Diretório Pombalino entrar em vigor na capitania de Goiás, a "pacificação" ocorria no momento em que uma determinada aldeia indígena tivesse sido totalmente destruída e seus habitantes mortos ou feitos como escravos, ou seja, a "paz" ${ }^{29}$ se dava na destruição física da alteridade, daí as diversas campanhas de guerra empreitadas contra os "Cayapó", principalmente as realizadas pelo sertanista Antônio Pires de Campos (ASNIS, 2018), aquele mesmo que primeiro mencionou o termo "Cayapó" nos registros históricos.

A pretensão dos colonizadores era alterar radicalmente a condição sociocultural e econômica dos nativos, instaurando outra ordem normativa e impedindo que os autóctones regressassem às suas crenças e práticas anteriores. Mas isto não acontecia, pois o adjetivo "pacificado" não indicava uma mudança mais profunda de costumes, apenas designava comunidades que haviam sido vencidas militarmente e que aceitavam temporariamente o domínio português. Com frequência, mal passados alguns anos, as mesmas comunidades e famílias, fossem premidas por novos interesses dos colonos, fossem motivadas pela necessidade de se lhes opor alguma forma desesperada de resistência, voltavam a entrar em choque com os agentes econômicos ou com a atividade de catequese. Uma nova "pacificação" era então empreendida pelos agentes do Estado, sempre em articulação com as demandas dos colonos e justificada por

\footnotetext{
29 "Paz" aqui entendida somente para os novos habitantes dos "sertões" brasileiros, ou seja, os colonos que iam se fixando nos territórios que estavam sendo "descobertos" pelos sertanistas. Ao se livrar das populações indígenas e destruí-las, estava garantida a "paz" para os não-índios.
} 
razões religiosas. Os inimigos, os "índios bravos" ou "rebelados", eram vistos como seres de uma natureza mais fraca e ambígua do que a dos europeus, e mais receptivos, portanto, "às artes do demônio" e as suas reiteradas investidas. (OLIVEIRA, 2016, p. 326) ${ }^{30}$

Como foi descrito no artigo, a necessidade de se fazer guerra contra essas populações indígenas se deu em virtude das alegorias da colonização, que buscavam de alguma forma justificar as ações dos agentes coloniais diante de povos nativos que "atrapalhavam" os interesses da coroa portuguesa no que se refere à exploração territorial da colônia. Em contrapartida, a necessidade de se fazer guerra por parte dos "Cayapó" se insere em uma questão cultural na qual a predação da alteridade (JUNQUEIRA, 2017) transforma aqueles que eram fracos e indefesos em corajosos, bravos e guerreiros, ou seja, através da violência e da vingança, os Kayapó se tornavam destemidos. Regidos por uma prática da estrutura, ou seja, a mitologia ${ }^{31}$ tornando-se contingencial, na história esses grupos Jê Meridionais orientavam suas ações com o mundo exterior não-índio utilizando como modelo as façanhas de seus heróis no tempo mítico “a história era interpretada pelo mito e esse fornecia as ferramentas da ação histórica" (MANO, 2015, p. 70).

Porém, como já destacado, após aproximadamente 40 anos de conflitos, foi necessário reconfigurar e redefinir as estratégias do contato para ambos os lados. Foram surgindo necessidades de mudanças práticas e simbólicas com relação ao confronto armado. Isso não significa que tenha havido uma ruptura total com relação aos confrontos, eles continuaram, mas muito mais associados às políticas dos poderes locais do que a dos ordenamentos da coroa portuguesa. ${ }^{32}$

\footnotetext{
${ }^{30}$ Mesmo o autor se referindo aos Tupinambás no século XVI, é possível fazer paralelos com o ocorrido entre as frentes coloniais que adentravam o Brasil central e os Jê Meridionais.

31 Ver o roubo do fogo (GORDON, 2006) e a luta dos dois irmãos contra o Grande Gavião (VIDAL, 1977), ambos mitos recolhidos entre os Xikrin-Mebêngokre.

32 Ver Coelho, 2013.
} 
O grande cerne é que agentes coloniais e indígenas estavam a todo momento agenciando uns aos outros, entretanto os únicos que obrigavam a alteridade a modificar seu modo de compreender o mundo eram os não-índios, eles que se viam na obrigação de revelar a "verdade" àqueles que estavam distantes dela, de levar a "paz" através da palavra de Deus e do trabalho forçado, de obrigar com que os indígenas, povos que habitavam a região a milhares de anos, passassem a aceitar de bom grado um novo modelo de sociedade, a sociedade "civilizada", ao contrário da "barbárie" em que esses povos viviam. Esses eram os reais intuitos da "pacificação". "Pacificar" não significava respeitar e conviver com as diferenças, "pacificar" significava impor, obrigar, usar como mão-de-obra. Mas por outro lado, os povos indígenas não foram totalmente reféns das políticas que vinham de fora, eles souberem agenciá-las e muitas vezes transformá-las a seu próprio favor. A história não lhes foi imposta, eles próprios a construíram a partir da realidade existente.

Dessa forma, chega-se à conclusão de que "guerra" e "paz" caminharam juntas. A necessidade de uma refletia a vontade sobre a outra. "Paz" é um conceito inalcançável desse período histórico, pois para alcança-la, era necessário transformar o "outro" no reflexo do "eu" e o que se vê é que essa transformação inexistiu, pois ela própria foi complexa e múltipla, construída através dos agenciamentos entre índios e não-índios e dificilmente seu resultado agradava os opostos. A guerra nunca chegou ao fim, ela sempre foi mascarada e denominada de maneiras diferentes. A "paz" é apenas uma ideia distante que só se concretizará no dia em que os diferentes se respeitarem e se entenderem, enquanto isso, ela se manterá entre aspas.

\section{Referências bibliográficas}

ALENCASTRE, J.P.M. "Annaes da Provincia de Goyaz". Revista do Instituto Histórico Geographico e Etnographico do Brasil, Tomo 27. Rio de Janeiro, 1864.

ALMEIDA, Maria Regina Celestino de. Os índios na História do Brasil. Rio de Janeiro: Editora FGV, 2010. 
AMADO, J. Região, Sertão, Nação. Estudos Históricos, Rio de Janeiro, v.8, n.5, p. 145-151, 1995.

AMANTINO, Márcia. O mundo das feras: Os moradores do sertão oeste das minas no século XVIII. São Paulo: Annablume, 2008.

APARÍCIO, JOÃO P. da S. Governar no Brasil Colonial: a administração de Luís da Cunha de Meneses nas capitanias de Goiás (1778-1783) e de Minas Gerais (17831788). Dissertação de mestrado. Lisboa: Universidade de Lisboa, 1998.

ASNIS, Gabriel Zissi Peres. O choque entre dois universos distintos e a guerra entre as frentes coloniais e os "Cayapó" Meridionais. Revista Nanduty, v. 6, p. 136-160, 2018.

ATAÍDES, Jézus Marco de. Sob o signo da violência: colonizadores e Kayapó do Sul no Brasil Central. Goiânia: Editora UCG, 1998.

BARBOSA, Alexandre de Souza. Descrição feita por Alexandre de Souza Barbosa sobre os índios Cayapós e os Panará. Vocabulário e mapa da região ocupada pelos Caiapós. 1918. Resgate Histórico de Odair Giraldin.

BARTH, Fredrik. Grupos étnicos e suas fronteiras. In: POUTGNAT, Philippe. Teorias da etnicidade. São Paulo: Fundação Editora da UNESP, 1998.

BATISTA DE MELO, Anderson. A política indigenista pombalina na capitania de Goyaz: o tempo de rendição (1772-1783). Dissertação (Mestrado). Brasília, UNB. 2008.

BHABHA, Homi K. O local da cultura. Belo Horizonte: Ed. UFMG, 1998.

BROCHADO, José Proenza. A tradição cerâmica Tupiguarania na América do Sul. CLIO: Revista de Pesquisa Histórica, PPGH - Universidade Federal de Pernambuco, 1980.

CAMPOS, Antonio Pires de. Breve notícia do gentio bárbaro que há na derrota das minas de Cuiabá e seu recôncavo, na qual declara-se os reinos [...]. In: TAUNAY, Afonso d'E. (org). Relatos Sertanistas. 2a ed. São Paulo: Livraria Martins Editora, 1976.

CANCELIER DIAS, Thiago. O língua e as línguas: aldeamentos e mestiçagens entre manejos de mundo indígenas em Goiás (1721-1832). Tese (Doutorado) Universidade Federal de Goiás, Faculdade de História, Programa de Pós-Graduação em História, Goiânia, 2017.

CHAIM, Marivone Matos. Aldeamentos indígenas: Goiás, 1749-1811 - 2.ed. ver. São Paulo: Nobel, 1983.

CHAIM, Marivone Matos. Aldeamentos indígenas: Goiás, 1749-1811. São Paulo: Nobel; Brasília: INL, Fundação Nacional Pró-Memória, 1983. 
COELHO, Mauro Cezar; SANTOS, Rafael Rogério Nascimento dos. “Monstruoso systema (...) intrusa e abusiva jurisdicção": o Diretório dos Índios no discurso dos agentes administrativos Coloniais (1777-1798). Revista de História, São Paulo, n. 168, p. 100-130, jan/jun, 2013.

DELEUZE, Gilles \& GUATARRI, Félix. Mil platôs: Capitalismo e esquizofrenia 2, vol.1. - São Paulo: Editora 34, 2011.

FREITAS, Ludmila Gomides. O sal da guerra: padre Antônio Vieira e as tópicas teológico-jurídicas na apreciação da guerra justa contra os índios. Tese (Doutorado) Universidade Federal de Uberlândia, Programa de Pós-Graduação em História, 2014.

GIRALDIN, Odair. “Cayapó e Panará". Luta e sobrevivência de um povo Jê no Brasil Central. Campinas: Editora da UNICAMP, 1994.

GIRALDIN, Odair. Fazendo guerras, criando imagens, estabelecendo identidades. A ocupação do centro-oeste e os conflitos com os Kayapó no século XVIII. História Revista, 6 (1), p. 55-74, jan/jun, 2001. https://doi.org/10.5216/hr.v6i1.10568

GORDON, Cesar. Economia selvagem - ritual e mercadoria entre os XikrinMebêngôkre. São Paulo: ed. da UNESP/ Instituto sócio ambiental, 2006.

JUNQUEIRA, Gabriela Goncalves. O visível e o invisível nas relações de contato dos grupos Jê Meridionais: uma análise da caça, guerra e dos rituais funerários como relações de predação, produção e controle dos poderes latentes da alteridade. Dissertação (Mestrado) - Universidade Federal de Uberlândia, Programa de PósGraduação em Ciências Sociais, 2017.

KARASCH, M. C. Catequese e cativeiro: Política indigenista em Goiás: 1780-1889. In: CUNHA, Manuela Carneiro da. História dos índios no Brasil - São Paulo: Companhia das Letras, 1992.

LARAIA, Roque de Barros. Tupi: Índios do Brasil atual. Editora: FFLCH, USP, 1986.

LOURENÇO, Luís A. B. Populações Indígenas e políticas Indigenistas no Triângulo Mineiro nos séculos XVIII e XIX. In: FILHO, Aurelino J. F. (org). Índios do Triângulo Mineiro - MG. História, arqueologia, fontes e patrimônio: pesquisas e perspectivas. Uberlândia, EDUFU, 2015.

MANO, Marcel. (Des)encontros culturais: um esboço parcial da história do contato dos Kayapó meridionais. In: Índios do Triângulo Mineiro: história, arqueologia, fontes e patrimônio: pesquisas e perspectivas. Aurelino José Ferreira Filho. (org). Uberlândia: Edufu, 2015.

MANO, Marcel. Contato, guerra e paz: problemas de tempo, mito e história. Política e Trabalho, n. 34, João Pessoa, p. 193-212, 2011. 
MANO, Marcel. Da Tradição à Cultura: problemas de investigação nos estudos das ocupações indígenas no Planalto Meridional brasileiro. Albuquerque: revista de história. vol. 10. № 19. jan-jul. 2018, p. 8-34.

MANO, Marcel. Os campos de Araraquara: um estudo de história indígena no interior paulista. Tese (Doutorado em Ciências Sociais - Antropologia). Universidade Estadual de Campinas, Campinas, 2006.

MANO, Marcel. Sobre as penas do gavião mítico: história e cultura entre os Kayapó. Tellus, n. 22, Campo Grande, jan-jun, 2012, p. 133-154.

MATTOS, Raymundo Jose da Cunha. Chorographia histórica da província de Goyaz. Goiânia: Líder, 1979.

MONTEIRO, John Manuel. Negros da terra: índios e bandeirantes nas origens de São Paulo. São Paulo: Companhia das Letras, 1994.

MONTEIRO, John Manuel. Tupis, Tapuias e historiadores: Estudo de História indígena e do Indigenismo. Tese apresentada para o concurso de livre docência na área de Etnologia, subárea História Indígena e do Indigenismo. Disciplinas HZ762 e H5119. Departamento de Antropologia IFCH - Unicamp. Campinas, agosto de 2001.

MORI, Robert. Os aldeamentos indígenas no Caminho dos Goiases: guerra e etnogênese no "sertão do Gentio Cayapó" (Sertão da Farinha Podre) - séculos XVIII e XIX. Dissertação de mestrado, 2015.

NASCIMENTO, Patrícia Emanuelle. Protagonismo indígena na capitania de Goiás e suas estratégias e atuações frente às políticas indigenistas no século XVIII. Tese (Doutorado em História). Universidade Federal de Goiás, Goiânia, 2019.

Notícias práticas das minas do Cuiabá e Goyazes, na Capitania de S. Paulo e Cuiabá, que dá ao Rev. Padre Diogo Soares, o Capitão João Antonio Cabral Camello, sobre a viagem que fez às Minas do Cuiabá no anno de 1727. Revista Trimensal de História e Geographia, ou Jornal do Instituto Histórico Geográphico Brasileiro, TOMO 4. Rio de Janeiro: Imprensa Americana de L.P. da Costa, 1842.

OLIVEIRA, João Pacheco de. O nascimento do Brasil e outros ensaios: "pacificação", regime tutelar e formação de alteridades. Rio de Janeiro: Contra Capa, 2016.

OLIVERIA, Machado de. Os Cayapó: Sua origem; descobrimento; acommettimentos pelos Mamelucos; represalia; meios empregados com violencia, e com arma em punho para subtrahil-os ás mattas; esses meios substituidos pelos de brandura; seus beneficos resultados; aldeamento; conclusão. Revista do Instituto Histórico e Geográfico Brasileiro. TOMO 24. Rio de Janeiro, 1973.

OSSAMI DE MOURA, M. C. Aldeamento carretão: "marco zero" da história das relações interetnicas dos Tapuios. Revista de História (UFES), v. 18, p. 28-48, 2006. 
POHL, Johann Emanuel. Viagem no interior do Brasil: empreendida nos anos de 1817 a 1821 e publicada por ordem de sua majestade o imperador da Áustria Francisco Primeiro. Rio de Janeiro: INL, 1951, vol.1.

SAHLINS, Marshall David. Ilhas de História. Rio de Janeiro: Jorge Zahar Ed., 1990.

SAHLINS, Marshall David. Metáforas históricas e realidades míticas: estrutura nos primórdios da história do reino das Ilhas Sandwich. Rio de Janeiro: Jorge Zahar Ed., 2008.

SAINT-HILAIRE, Auguste de, 1779-1853. Viagem à província de Goiás. Belo Horizonte, Ed. Itatiaia; São Paulo, Ed. da USP, 1975.

SOUSA E SILVA, Joaquim Norberto de. "Biographia: Damiana da Cunha". Revista do Instituto Historico Geographico e Etnographico do Brasil, Tomo 24 (1861), 1973.

Subsídios para a história da Capitania de Goiaz (1756 - 1806). Revista do Instituto Histórico e Geográfico Brasileiro, TOMO 84. Rio de Janeiro: Imprensa Nacional, 1919.

TURNER, Terence. Os Mebengokre Kayapó: história e mudança social, de comunidades autônomas para a coexistência interétnica. In: CARNEIRO DA CUNHA, M. (org). História dos índios no Brasil. São Paulo: Cia das Letras, 1992, p. 311-338.

URBAN, G. A História da cultura brasileira segundo as línguas nativas. In: CARNEIRO DA CUNHA, M. (org). História dos índios no Brasil. São Paulo: Cia das Letras, 1992, p. 87-102.

VIDAL, Lux Boelitz. Morte e vida de uma sociedade indígena brasileira: os KayapóXikrin do rio Cateté. São Paulo, HUCITEC, Ed. da Universidade de São Paulo, 1977.

WAGNER, Roy. A invenção da Cultura. São Paulo: Cosac Naify Portátil, 2012. 